\title{
Design and Development of Student Data Retrieval System via GSM
}

\author{
Idachaba F.E, Ajaja O, Oke-Salako T, Ibioku. A, Odejobi. M, \\ Fabiyi. A and Odigwe I.A \\ ${ }^{+}$Department of Electrical and Information Engineering Covenant University Ota. Ogun State. Nigeria
}

\begin{abstract}
Remote data access and machine to machine communication are some of the value added services made possible by the GSM communication technology. With this service, automated access to records, information and updates can be achieved by the use of the GSM short message system (SMS) queries. This work presents the development of a remote access platform for remote access to a database. The system utilizes the GSM-SMS technology and an interactive voice recorder system to access data. The database contains students result, financial status and information on the number of exeats taken. This data is accessed by calling dedicated phone number and following the voice prompt voice prompt, the user is able to access the desired information from the database. Once the required data is accessed, the GSM module transmits this query result back to the caller in SMS format. The system provides a cost effective channel for accessing data from remote databases.
\end{abstract}

Keywords: Data Access, Database, Interactive Voice Recorder, GSM, SMS.

\section{Introduction}

Interactive voice response is a telephony feature in which a touch tone telephone enables interaction with a database to acquire information. The interactive voice response system has been put into operation in variety of ways such as in bank balances, flight and movie schedules, so that registered customers can receive up-to-date information instantly. IVR technology is also used to gather information, as in the case of telephone surveys in which the user is prompted to answer questions by pushing the numbers on a touch-tone telephone. This project will apply IVR in college environment from result querying, college alerts and student's exeat status. Current information such as results, class attendance status, and school fees (financial status) for the students can be accessed remotely from a comprehensive data base containing all the information pertaining to the student. The work involves the creation of interfaces through which the concerned staff (lecturers and students affairs department) can upload the student's data into the central database computer and users assessing the information on the database via the GSM technology.

\section{System Analysis And Design}

The realization of this project involves the creation of the database and the user interfaces for the Lecturers, the porters and the financial service units. It also involves the programming of the GSM modem for playback and interactive voice response systems

\section{Database}

The central database will hold all information pertaining to all students. This information which will be supplied by the lecturers, porters and financial service officials will include the student's results, class and hall attendance status, exeats taken by student, and financial status. The system will provide the lecturers, porters and financial service staff with an interface through which they can input their data. The database is thus, updated as often as the staff have new information to input. Visual Basic will be used to develop the interfaces on the various systems.

\section{Hardware}

When the user dials the designated number (number of the SIM card attached to GSM modem) a voice response is activated requesting the user to enter the Pin number on the Student Data Retrieval Card. A correct pin grants access to the database. When granted access, the voice menu playback is triggered guiding the user through the menu. When the desired value is selected, the user is asked to enter a valid student ID. The system confirms the digits typed in with the user before querying the database. The database is queried based on the user's input and the result is sent to the caller in form of SMS. The system block diagram is shown in Figure 1. 


\begin{tabular}{|c|c|c|}
\hline $\begin{array}{l}\text { GSM Module receives } \\
\text { incoming call from user }\end{array}$ & $\begin{array}{l}\text { Voice menu/instructions } \\
\text { plays back to the user over } \\
\text { the GSM network }\end{array}$ & $\begin{array}{l}\text { User responds to voice menu } \\
\text { by pressing } 1,2,3 \text { or } 0 \\
\text { according to instructions }\end{array}$ \\
\hline $\begin{array}{l}\text { GSM Module sends } \\
\text { retrieved data back to caller } \\
\text { Via SMS }\end{array}$ & $\begin{array}{l}\text { Database is queried based on } \\
\text { parameters obtained from } \\
\text { DTMF decoder }\end{array}$ & $\begin{array}{l}\text { DTMF Decoder decodes } \\
\text { user's input }\end{array}$ \\
\hline
\end{tabular}

Figure 1: Block diagram of Query aspect of the project

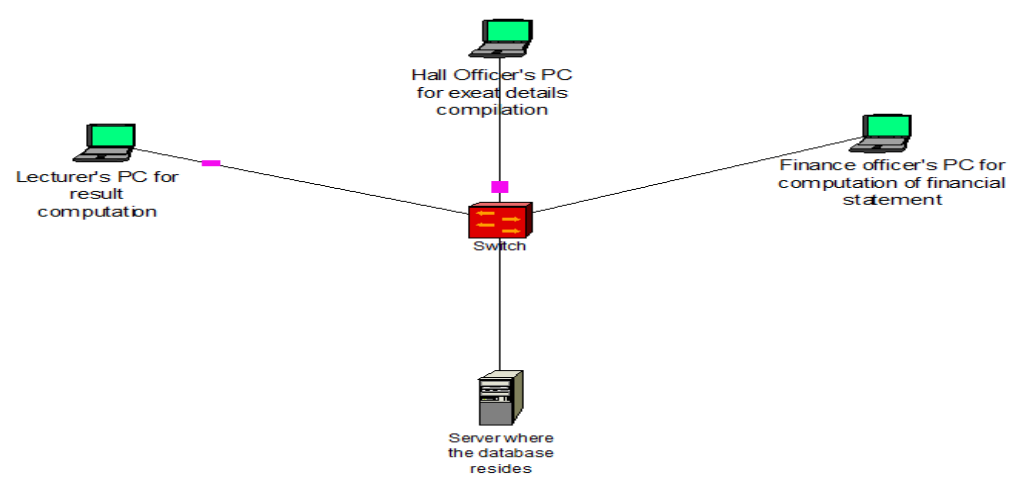

I. Figure 2: The connection of several systems to a server showing the backend process.

\section{BACKEND PROGRAMS}

Figure 2 show the interconnection of the different systems to the server. The backend program for the project contains modules which will be used for populating the database to be queried based on callers' requests. The data that will be fed into the database from these modules are students' results, residential details and financial statement of the students from the lecturer's interface, hall officer's interface and financial officer's interface respectively. The interfaces that will be made available under the different modules are shown in a chart in Figure 3.

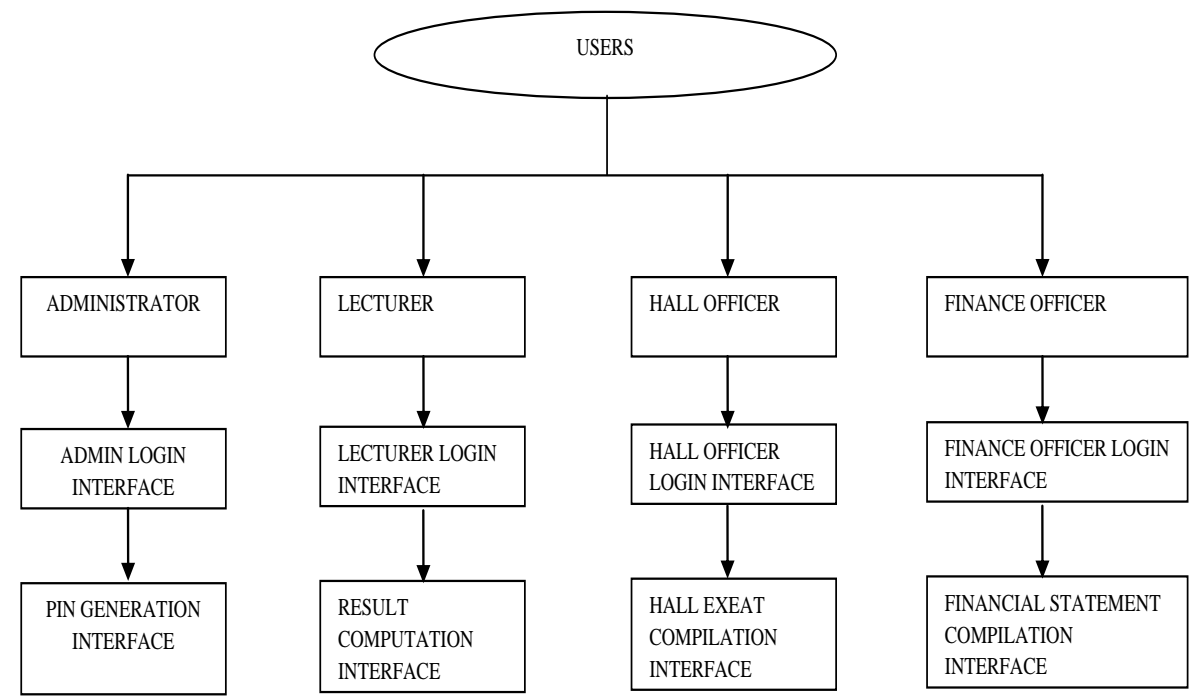

Figure 3 Components of the Backend program 


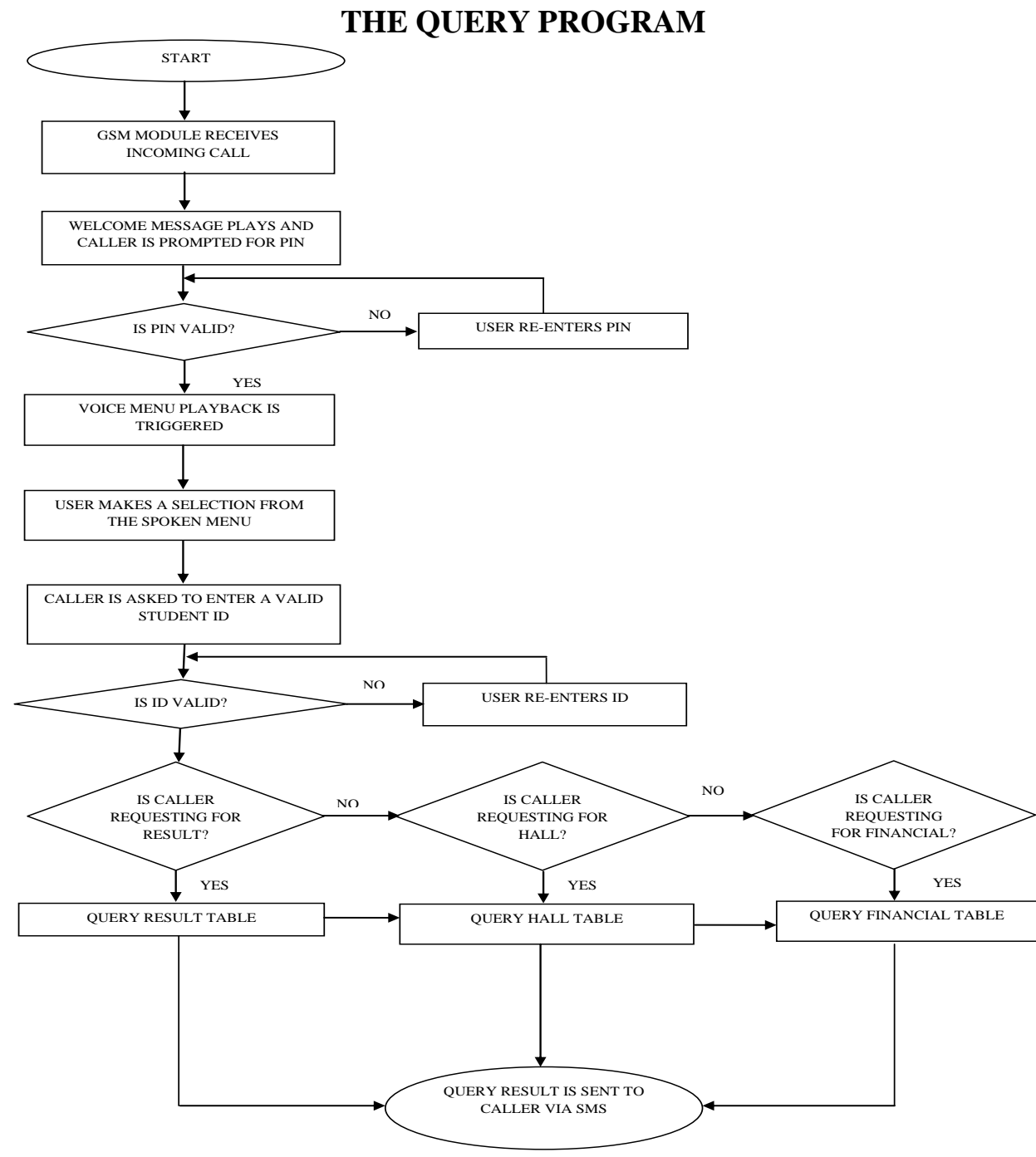

Figure 4. Flowchart of VB Database Query program

Figure 4 shows the flowchart of the database query program. This program queries the database based on the user's selection from the spoken menu. The decoder decodes the selection made and a string is returned which is used to query the database. If the user selects option ' 1 ', (retrieval of results), the DTMF decoder returns the string "RESULT" which is used to query the result database after the caller must have keyed in the necessary pin for access into the system. The flowchart of the query program is shown in Figure 4

\section{The Database Structure}

The database is a repository for student results, residential information, financial statements, archives and log. This could be implemented using Microsoft access, Microsoft SQL Server or My SQL databases. There are two databases to be designed in all. They are:

THE STUDENTS_INFO DATABASE: The students_ info database contains general information about the students. The database contains the results table, the hall table and the financial table.

THE ADMIN DATABASE: The admin database holds the data of the users of the system where the users include; lecturers, hall officers and finance officer. It is also a repository of the PIN codes that will be used to access the service, including used and unused PIN codes and student's matriculation number matched with their student ID.

\section{SYSTEM IMPLEMENTATION AND TESTING}

\section{Database query implementation}

The database which will be queried was implemented using MySQL database. It has three tables called result, hall and financial and it is resident on the server. These three tables serve the purposes of result query, hall attendance query and financial statement query respectively. 
The result table was structured in a way that the matriculation number of the student is tabulated against the courses the student offers and the grades merited in those courses. A view of the table is presented in Figure 5

\begin{tabular}{|c|c|}
\hline MATRIC & CEN520 \\
\hline 04CJ01271 & $B$ \\
\hline $04 C J 01272$ & B \\
\hline $04 C J 01273$ & A \\
\hline $04 C J 01274$ & \\
\hline 04CJ01275 & \\
\hline $04 C J 01276$ & B \\
\hline $04 C J 01280$ & A \\
\hline 04CJ01281 & A \\
\hline 04CJ01283 & A \\
\hline $04 C J 01285$ & A \\
\hline $04 C J 01286$ & B \\
\hline $04 C J 01287$ & c \\
\hline $04 C 101292$ & B \\
\hline $04 C J 01293$ & A \\
\hline 04CJ01294 & A \\
\hline 04CJ01295 & D \\
\hline $04 C J 01296$ & c \\
\hline $04 C J 01300$ & D \\
\hline 04CJ01301 & \\
\hline 04CJ01303 & B \\
\hline 04CJ01305 & B \\
\hline 04CJ01306 & c \\
\hline 04CJ01308 & c \\
\hline 04CJ01310 & B \\
\hline 04CJ01311 & A \\
\hline $04 C J 01312$ & B \\
\hline $04 C J 01315$ & B \\
\hline
\end{tabular}

\begin{tabular}{|l|l|l}
\hline CEN521 & CEN \\
\hline & \\
B & \\
B & \\
B & \\
B & A \\
B & A \\
A & A \\
A & A \\
B & A \\
B & A \\
B & A \\
A & \\
A & \\
B & \\
B & \\
C & \\
B & \\
B & A \\
A & A \\
C & A \\
C & B \\
A & A \\
B & A \\
A & B \\
\hline &
\end{tabular}

\begin{tabular}{lll} 
CEN522 & CENE \\
B & A \\
B & B \\
B & A \\
B & B \\
A & A \\
A & B \\
A & A \\
A & B \\
A & B \\
A & C \\
B & B \\
B & B \\
B & A \\
B & A \\
B & B \\
B & B \\
D & B \\
D & C \\
A & A \\
A & B \\
A & A \\
C & B \\
B & B \\
A & B \\
A & A \\
C & B \\
B & B \\
\hline
\end{tabular}

\begin{tabular}{|c|c|c|}
\hline CEN524 & EIE520 & EIE521 \\
\hline c & c & \\
\hline B & B & B \\
\hline B & B & A \\
\hline A & B & A \\
\hline B & B & B \\
\hline$A$ & B & A \\
\hline A & B & A \\
\hline A & c & $A$ \\
\hline $\mathrm{A}$ & B & A \\
\hline $\mathrm{A}$ & B & A \\
\hline A & c & B \\
\hline B & $A$ & A \\
\hline A & B & A \\
\hline $\mathrm{A}$ & c & A \\
\hline $\mathrm{A}$ & $A$ & A \\
\hline B & C & B \\
\hline$A$ & c & B \\
\hline c & B & B \\
\hline$A$ & B & B \\
\hline B & A & B \\
\hline A & B & B \\
\hline B & B & B \\
\hline B & c & A \\
\hline B & क्षण & A \\
\hline A. & mones & \\
\hline B & HणVL & \\
\hline & & \\
\hline
\end{tabular}

Figure 5: A view of the Result table

\begin{tabular}{|c|c|c|c|}
\hline & EIE529 EIE.. & GPA & CGPA \\
\hline B & & & \\
\hline & novers & 4.3 & 3.54 \\
\hline A & nuvere & 4.61 & 3.58 \\
\hline & 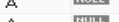 & & \\
\hline & पूver & 4.32 & \\
\hline & माण्ड & 491 & \\
\hline & Hover & 4.74 & 4.52 \\
\hline$\Delta$ & Hore & 4.83 & 4.52 \\
\hline & Houre & 4.61 & 3.59 \\
\hline & 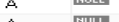 & & 3.57 \\
\hline & पूण & 年. & $\begin{array}{l}3.58 \\
3.98\end{array}$ \\
\hline & मrver & 4.74 & 362 \\
\hline & Hevere & 4.83 & 3.64 \\
\hline & माvere & 4 & 3.55 \\
\hline & Horte & 4.09 & 3.57 \\
\hline B & 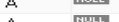 & 3.65 & 3.52 \\
\hline & Hover & 4.74 & $\begin{array}{l}3.65 \\
3.67\end{array}$ \\
\hline & Horte & 47 & \\
\hline & Herte & 3.74 & 3.55 \\
\hline & Herte & 4.13 & 3.6 \\
\hline & Hoves & 4.17 & 3.61 \\
\hline & rovere & $\begin{array}{l}4.57 \\
.397\end{array}$ & $\begin{array}{l}3.66 \\
3.56\end{array}$ \\
\hline & Hever & 3.85 & $\begin{array}{l}3.58 \\
359\end{array}$ \\
\hline
\end{tabular}

The hall table was structured in a way that the name and matriculation number of the student is tabulated against the room number, exeat details and roll call details of the student. A view of the completed table is shown in Figure 6

\begin{tabular}{|c|c|}
\hline MATAIC & PROGAAM \\
\hline 04[J101272 & EEN \\
\hline $\begin{array}{l}04 C 101274 \\
04 \div 101275\end{array}$ & $\begin{array}{l}\text { CEN } \\
\text { CEN }\end{array}$ \\
\hline $04 \subset J 01280$ & CEN \\
\hline 04โJJ17283 & EEN \\
\hline 04CJ01292 & CEN \\
\hline 04CJ01293 & CEN \\
\hline $04[101303$ & CEN \\
\hline a4C.J01305 & CEN \\
\hline 04CJ01325 & CEN \\
\hline $\begin{array}{l}04[101327 \\
04[101330\end{array}$ & $\begin{array}{l}\text { CEN } \\
\text { CEN }\end{array}$ \\
\hline $\begin{array}{r}04501330 \\
04 \cdot 101332\end{array}$ & $\begin{array}{l}\text { CEN } \\
\text { CEN }\end{array}$ \\
\hline 04CJ01333 & CEN \\
\hline 04CJ01343 & CEN \\
\hline O4CJ01344 & CEN \\
\hline 04CJ01347 & CEN \\
\hline 04CJ01357 & CEN \\
\hline $\begin{array}{r}04 C D 101364 \\
040.01366\end{array}$ & $\begin{array}{l}\text { CEN } \\
\text { CEN }\end{array}$ \\
\hline Q4CJ01368 & CEN \\
\hline $04 C J 01370$ & CEN \\
\hline 04CJ01372 & CEN \\
\hline $04[101373$ & CEN \\
\hline Q4CJ01381 & CEN \\
\hline C & DEN \\
\hline
\end{tabular}

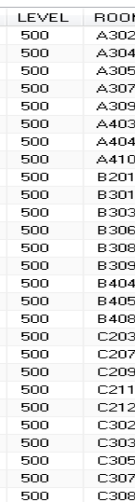

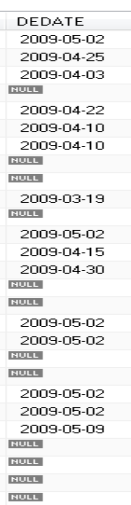
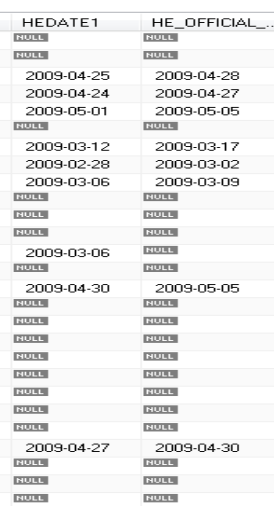

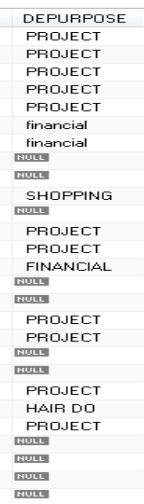

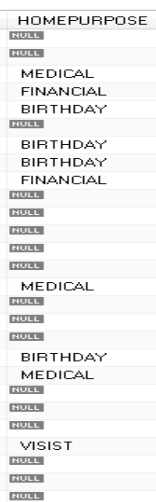

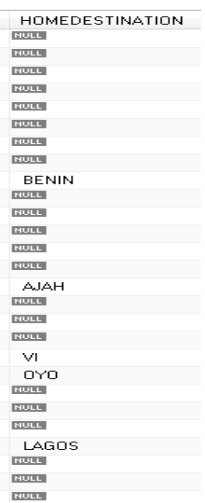

The financial table was structured in a way that the name and matriculation number of the student is tabulated against the financial statement of the student.

\section{Voice menu playback}

The voice menu playback is implemented using VB.NET and it is resident on the server. Once an incoming call is detected, voice playback is activated and the welcome message is played to the caller. When a call comes in, the welcome message ("Welcome to Covenant University Automated Service") is played back for the caller after which the caller is immediately prompted for an 8 digit Pin number to gain access into the system ("Please enter your 8 digit Pin to access this system"). If the pin is correct, the voice menu playback begins. The menu is listed below:

$>$ Press 1 to retrieve the student's results

$>$ Press 2 to retrieve the student's residential details

$>$ Press 3 to retrieve the student's financial statement

$>$ Press 0 to repeat the menu

In the event of a wrong pin the system plays an invalid message and prompts the user to try again ("The pin you entered is incorrect. Please enter the correct pin"). Once the caller makes a selection, he is prompted for the student ID ("Please Enter your student ID") so that the student whose information will be retrieved can be identified by the system. When this is done, the goodbye message ("Your 'result' will be sent to you shortly. Thank you for visiting. Goodbye") will be sent to the caller's phone. 'Result' will be replaced with 'hall details' or 'financial statement' depending on the user's selection.

\section{Database query results}

\section{Results}

The results based on the queries are sent as Text messages to the requester based on the queries. There are three formats for the three different query options. 
1. If the user queries the result table, the format of the text received is "AJAJA OLAMIDE CEN520: A, CEN521: A, CEN522: A, TMC521: A... GPA:4.9, CGPA:4.51"

2. If the user queries the hall table, the format of the text received is "AJAJA OLAMIDE, ROOM (LYDIA H209), DAY EXEAT (DATE: 22/4/2009; PURPOSE: financial: DESTINATION: Ekiti) HOME EXEAT: 0 "

3. If the user queries that financial table, a format of the text received is "AJAJA OLAMIDE 500L, AMOUNTPAID: 405000NGN, AMOUNTDUE: 24000NGN"

I.

\section{BACK-END PROGRAMS INTERFACES}

\section{The lecturer's application}

The lecturer's login interface: This interface was designed to provide security to the system. Only the lecturers that have been registered in the database by the administrator will be allowed to log into the system. The interface provided for this purpose is shown in Figure 7

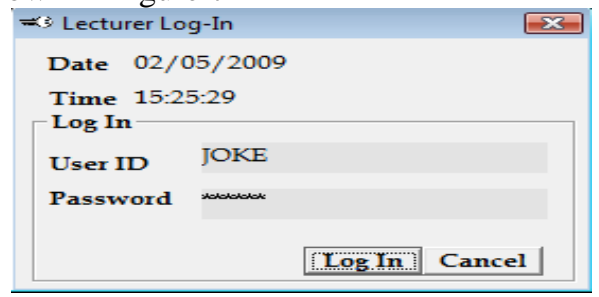

Figure 7: Lecturer's Log-in Interface

The Result computation interface: This interface was developed for the purpose of populating the central database with students' results as inputted by the lecturers. Only the course(s) been taken by the lecturer are loaded into the form with students who have registered for the course have their matriculation number loaded into the combo box named 'Matric. Number. Once a Matric number is selected, other details are automatically displayed on the form and the total Scores,

\section{The hall officer's application}

The interface for the hall officer's log-in is very similar to that of the lecturer's log-in interface with the exception that the caption reads "Hall Officer Log-In" and only registered hall officers can login to access the system. The exeat details interface is for the purpose of saving the exeat details of the students residing in a particular hall of residence into the central database. A screenshot of the interface is shown in figure 8. Only the students residing in the hall officer's hall of residence have their names loaded into the form for action by the hall officer. Once the name or Matriculation number is selected, the student's other details such as room number, program, level, etc. will be automatically loaded into the form. The username of the currently logged in hall officer is always shown in the status bar at the base of the form

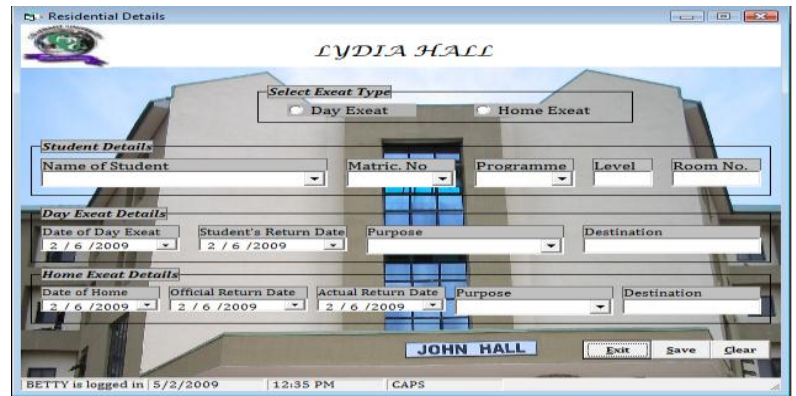

Figure 8: A screenshot of the Residential Details interface

\section{The finance officer's application}

The login interface: Similar to the Hall Officer's login and the Lecturer's login. The financial statement interface provides the finance officer with an avenue to key in the financial status of every student into the database. A screenshot of this interface can is shown in Figure 9. The Fees that are common to certain groups of students are automatically displayed once the user selects a student. The total fees to be paid by the student is automatically calculated and displayed. The user name of the currently logged in staff is displayed in the status bar 


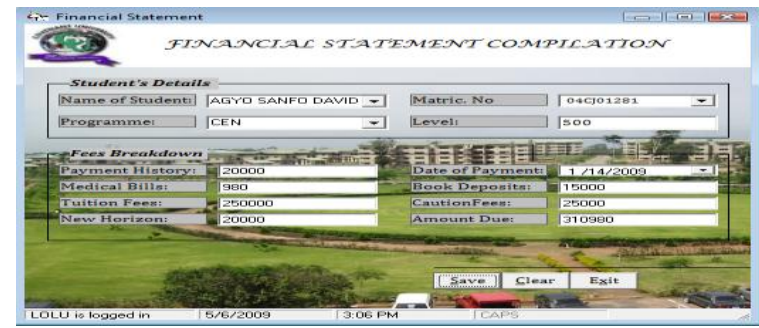

Figure 9: A screenshot of the Finance Details interface

The administrator's interface

The administrator interface comprise of the admin login interface and the pin generation interface

\section{Summary and Conclusion}

The students' database retrieval/access system provides a means for accessing the results, exeat status and financial record of students by allowing parents utilize their mobile phones to query the student's database located in the school. This eliminates the need to travel to the school thereby reducing the cost and time required to access student's information. The system can be applied to other applications where data access is required:

\section{References}

[1] Steenderen, M.V. (2002), "Business application of WAP", The Electronic Library, Vol.20 No.3, pp. 215-23.

[2] http://ferl.becta.org.uk/display.cfm[Online] Mayer, I. (2002), "Using text messaging to improve student organization and motivation"

[3] http://www.gsmworld.com/technology/sms/index.html [Online] GSM Association "SMS (Short Message Service)"

[4] GSM Association (July 2000) "What is SMS?"'Online] Available at:http://www.gsmworld.com/Technology/sms/intro.html

[5] IEC Online Education,"Wireless Short Message Service(SMS)",[Online] Available at: http://www.iec.org/online/tutorials/wire_sms

[6] Zapf F., "Telephone-controlled switch", Elekton Electronics, pp 58-65, Jan 1994

[7] Mitel, "MT8870 Integrated DTMF Receiver", MITEL telephone, Chapter 4, pp 11-21, Aug 1996.

[8] Tocci R.J, “Digital System, Principles and Applications”, Prentice Hall, 2001

[9] Lenk J.D., "Complete guide to Telephone Equipment””, 1999 